\title{
Cresolase, catecholase and laccase activities in haemocytes of the red swamp crayfish
}

\author{
Washington Cárdenas and John R. Dankert* \\ Department of Biology, Immuno-Ecology Laboratory, University of \\ Southwestern Louisiana, Lafayette, LA 70504, U.S.A.
}

(Received 16 November 1998, accepted after revision 31 May 1999)

\begin{abstract}
Phenoloxidase activity in crayfish haemocyte lysates and extracts of haemocyte membranes were studied using native PAGE and SDS-PAGE gels and staining for cresolase, catecholase and laccase activities. The activation of the proenzyme, prophenoloxidase to phenoloxidase, in native PAGE was demonstrated following exposure to SDS. By staining samples separated in SDSPAGE followed by renaturation, a high molecular mass phenoloxidase activity was identified in both the soluble and membrane fractions of haemocyte preparations. The membrane-associated activity appeared at only relatively high molecular mass $(>300 \mathrm{kDa})$, and could easily be eluted from membranes using detergents or $\mathrm{NaCl}$. Further, this membrane-associated activity has a catecholase activity but not the cresolase activity seen in the soluble preparations. In addition, several other phenoloxidase enzymes were identified with different relative mobilities (250, 80, 72 and $10 \mathrm{kDa})$. Crayfish haemocytes also contained laccase activity, thought to be restricted to cuticle sclerotisation in the integument. Laccase activity in haemocytes might aid in the formation of capsule used to contain pathogens. $\quad$ (C) 2000 Academic Press
\end{abstract}

Key words: phenoloxidase, laccase, crayfish haemocytes, electrophoresis.

\section{Introduction}

Humoral and cellular components are key elements of the invertebrate innate immune system. Both components are enhanced by the action of the prophenoloxidase activating system (proPO) which has been identified in several invertebrates, and is also involved in the nonself recognition of these animals (Canicatti \& Götz, 1991; Jackson et al., 1993; Söderhäll et al., 1994). This enzyme system appears to be a widespread defence mechanism also present in plants (Boss et al., 1995; Thipyapong et al., 1995).

Phenoloxidase (PO), the activated form of proPO, has received a great deal of attention in arthropods (Götz \& Boman, 1985; Söderhäll et al., 1994). This enzyme is present within circulating haemocytes (Smith \& Söderhäll, 1991; Cárdenas \& Dankert, 1997; Perazzolo \& Barracco, 1997) and in haemolymph (Ashida, 1971; Andersson et al., 1989). PO is also localised on haemocyte cell surfaces (Charalambidis et al., 1996). Phenoloxidases associated with

*Correspondence author. E-mail: dankert@usl.edu 
arthropod cuticles have been described for different species (Barrett, 1987a; Binnington \& Barrett, 1988; Thangaraj \& Aruchami, 1992). One of these enzymes appears to be involved in wound-healing reactions (Barrett, 1984) and is similar to haemocyte PO. Wound-healing and haemocyte POs are tyrosinase-type enzymes with cresolase (EC 1·14.18.1) and catecholase (EC $1 \cdot 10 \cdot 3 \cdot 1$ ) activities. Laccase (EC 1·10.3.2), another cuticle PO (Barrett \& Andersen, 1981), can oxidise both $o$ - and $p$-diphenols. Laccase seems to be restricted to integumental tissues and has not been reported in circulating haemocytes (Charalambidis et al., 1994).

Purified proPO and cuticle $\mathrm{PO}$ have been obtained as a single protein or as a dimer (Andersson et al., 1989; Aspán \& Söderhäll, 1991; Hall et al., 1995; Kopácek et al., 1995).

Native forms of these enzymes are usually characterised by having molecular masses >100 kDa (Barrett, 1987b; Hall et al., 1995; Kopácek et al., 1995). Such studies have assayed substrate specificity of purified or crude extracts of PO spectrophotometrically. Detection of immobilised PO after gel electrophoresis has also been described (Nellaiappan \& Vinayagam, 1986; Nellaiappan \& Banu, 1991). This latter technique is useful to detect PO enzymes and the associated molecular mass in crude extracts without the necessity for enzyme purification. Furthermore, the effect of endogenous enzyme inhibitors can be avoided and detection of PO activity is highly sensitive.

To further understand the enzymatic properties of the PO, considered to be important in the innate immune system of arthropods, we have studied the activity of this enzyme system in the commercially important red swamp crayfish Procambarus clarkii. Enzymatic activity was detected in haemocyte lysate supernatants and extracts of haemocyte membranes after sodium dodecylsulphate polyacrylamide gel electrophoresis (SDS-PAGE) to detect molecular mass differences. Substrate specificity (using various chromogenic substrates), enzyme inhibition and the effect of $\mathrm{pH}$ were also examined.

\section{Materials and Methods}

CHEMICALS AND REAGENTS

Substrates L-tyrosine methyl ester, 4-methyl catechol, L-3,4dihydroxyphenylalanine (L-DOPA), dopamine, 3,3'-diaminobenzidine (DAB) and hydroquinone were obtained from Sigma (St. Louis, MO, U.S.A.). 3-Methyl-2-benzothiazolinone hydrazone hydrochloride (MBTH), diethyldithiocarbamic acid (DETC), cholic acid, Triton X-100, trypsin, phenylmethyl sulfonyl fluoride (PMSF), and mushroom tyrosinase were also from Sigma. 3,3-dimethylglutaric acid (DMG) was from US Biochemical Corp. (Cleveland, $\mathrm{OH}$, U.S.A.). Molecular weight standards BenchMark protein ladder and BenchMark prestained protein ladder were from Life Technologies (Grand Island, NY, U.S.A.).

Protein concentration was determined by the microtitre protein assay of Bio-Rad (Hercules, CA, U.S.A.), using BSA as standard. 
HAEMOCYTE LYSATE SUPERNATANT (HLS)

Procambarus clarkii were generously provided by Dr J. Huner from the Crayfish Research Center, University of Southwestern Louisiana, Lafayette, LA, U.S.A. Animals were maintained as described before (Cárdenas \& Dankert, 1997). Haemolymph was extracted from one or more apparently healthy animals with a $5 \mathrm{ml}$ syringe containing $2 \mathrm{ml}$ of ice-cold anticoagulant buffer (AB) (Smith \& Söderhäll, 1983). Diluted haemolymph was quickly centrifuged at $750 \times \mathrm{g}$ at $4^{\circ} \mathrm{C}$ for $15 \mathrm{~min}$. Supernatant (plasma) was discarded and the cell pellet resuspended in $1 \mathrm{ml}$ of $\mathrm{AB}$ and centrifuged at $725 \times \mathrm{g}$ at $4^{\circ} \mathrm{C}$ for $10 \mathrm{~min}$. The supernatant was discarded and the cell pellet resuspended in a PBS-Vanadate buffer (10 mm potassium phosphate buffer, $150 \mathrm{~mm} \mathrm{NaCl}$, $\left.1 \mathrm{~mm} \mathrm{Na}_{3} \mathrm{VO}_{4}, \mathrm{pH} 6.8\right)$ and centrifuged under similar conditions. The supernatant was discarded and $200 \mu \mathrm{l}$ of lysing buffer was added (LyB-PMSF, $20 \mathrm{~mm}$ Tris, $5 \mathrm{~mm}$ EDTA, $1 \mathrm{~mm} \mathrm{Na}_{3} \mathrm{VO}_{4}, 1 \mathrm{~mm}$ PMSF, $\mathrm{pH}$ 7.6). The haemocyte pellet was homogenised with a motor driven drill at full speed with a sterile polypropylene pestle, on ice for $1 \mathrm{~min}$. LyB-PMSF was then added to complete $1 \mathrm{ml}$. The homogenate was centrifuged at $16000 \times \mathrm{g}$ at $4^{\circ} \mathrm{C}$ for $30 \mathrm{~min}$. The supernatant (HLS) was kept on ice until needed.

\section{HAEMOCYTE MEMBRANES SUPERNATANT (HMS)}

The pellet obtained after the $16000 \times g$ centrifugation was resuspended in $1 \mathrm{ml}$ of LyB-PMSF, vortexed and centrifuged at $16000 \times \mathrm{g}$ at $4^{\circ} \mathrm{C}$ for $10 \mathrm{~min}$. This treatment was repeated. The cell membranes were resuspended a third time in LyB without PMSF and centrifuged. Then the membranes were resuspended in $1 \mathrm{ml}$ of either: $\mathrm{LyB}$, LyB with $1 \%$ cholic acid, LyB with $1 \%$ Triton X-100, LyB with $0.5 \mathrm{M} \mathrm{NaCl}$, or LyB with $1 \mathrm{mg} \mathrm{ml}^{-1}$ trypsin. Tubes from each treatment were incubated at $4^{\circ} \mathrm{C}$ on an end-over-end shaker for $1 \mathrm{~h}$. After incubation, all tubes were centrifuged at $16000 \times g$ as above. Supernatants (HMS) were kept on ice until needed.

\section{ELECTROPHORESIS AND PHENOLOXIDASE ACTIVITY}

Phenoloxidase activity was detected on polyacrylamide gels as described by Nellaiappan \& Vinayagam (1986) with some modifications. HLS and HMS were run in a $4-20 \%$ gradient SDS-PAGE system using a Mini-PROTEAN II Cell (Bio-Rad) under non-reducing conditions. Samples were not boiled unless specified. HLS proteins were also separated in similar polyacrylamide gels, but under non-denaturing conditions (native gel, no SDS added). After electrophoresis, SDS-PAGE gel was washed $2 \times 10$ min in $2.5 \%$ Triton X-100 in $50 \mathrm{~mm}$ phosphate buffer, $\mathrm{pH} 6.5$. A last $10 \mathrm{~min}$ wash was made in phosphate buffer without Triton. The gel was then incubated in a 4:1 ratio of substrate solution (10 mM) dissolved in phosphate buffer and MBTH $(0 \cdot 3 \%)$ dissolved in deionised water (DI). The gel was developed for $1 \mathrm{~h}$ and then rinsed with DI several times. The gel was submerged in a $7 \%$ acetic acid solution and dried. For inhibition studies, the gel was treated with DETC (10 mM) in phosphate buffer after Triton X-100 (see above). Before the gel was developed in the substrate mixture, it was washed $2 \times 5$ min with phosphate buffer. Native gels 
were only treated with phosphate buffer before substrate addition. For proPO activation, native gels were exposed to SDS $(0 \cdot 1 \%$ in phosphate buffer) for about $15 \mathrm{~min}$ and then processed as SDS-PAGE gels.

The effect of $\mathrm{pH}$ on phenoloxidase activity was studied using $50 \mathrm{~mm}$ DMG. This wide range buffer allows testing to be performed at different $\mathrm{pH}$ values without changing the buffer used. The $\mathrm{pH}$ values ranged from $3.5-7.5$ in 0.5 units of increment, giving a total of nine different values. When the electrophoresis was finished, the gel was treated with $2.5 \%$ Triton X-100 dissolved in DI. The gel was briefly ( $\sim 10 \mathrm{~min})$ incubated in each respective $\mathrm{pH}$ solution. The buffer solution was discarded and $10 \mathrm{~mm}$ of the required substrate dissolved in DMG at the corresponding $\mathrm{pH}$ was added. MBTH was added following the substrate and the whole mixture incubated for an hour for development.

The molecular mass of PO activity bands were estimated with prestained molecular weight markers that were run together with HLS and HMS proteins. Prestained markers were calibrated against Coomassie blue stained molecular weight markers.

\section{Results}

Phenoloxidase (PO) in this report makes reference to the enzyme that has both catecholase (oxidation of $o$-diphenols) and cresolase (o-hydroxylation of monophenols) activity. Laccase is a PO that can oxidise $o$ - and $p$-diphenols, and does not have cresolase activity.

Native gels stained with 4-methyl catechol showed only a trace of PO activity (Fig. 1a), but this was greatly enhanced when polyacrylamide gels were exposed to SDS (Fig. 1b). Boiling of HLS proteins $\left(100^{\circ} \mathrm{C}\right.$ for $5 \mathrm{~min}$ ) before native gel electrophoresis abolished any detectable PO activity as assessed by 4-methyl catechol oxidation with or without SDS pretreatment (Fig. 1c). The observed background PO activity (Fig. 1a) might be due to the nucleophile MBTH present in the substrate mixture (Nellaiappan et al., 1989).

PO activity detected through the use of catechol in HLS after SDS-PAGE showed a series of bands with molecular masses that ranged from 10 to $>500 \mathrm{kDa}$ (Fig. 2a). Most of the PO activity was developed at high molecular mass bands and concentrated on two bands of 400 and $370 \mathrm{kDa}$. In order to test for the presence of cresolase and laccase activity, tyrosine and DAB were used as substrates, respectively. One band of activity was developed for cresolase (Fig. 2d), and four or more bands were developed for laccase (Fig. 2g). DAB, a substrate for peroxidases, has been used to detect laccases in arthropod cuticle (Binnington \& Barrett, 1988). Since peroxidases are able to oxidise catechol substrates (Okun et al., 1972), gel strips were preincubated with the copper-chelator and PO inhibitor diethyldithiocarbamic acid (DETC) before development in the respective substrates. This treatment was effective in abolishing any detectable cresolase, laccase and most of the catecholase activity (Fig. 2b, e, h). In order to test the specificity of the enzymatic assay, purified mushroom tyrosinase was included in the activity gels. Catechol staining of this enzyme depicted two doublet forms with fast and slow 


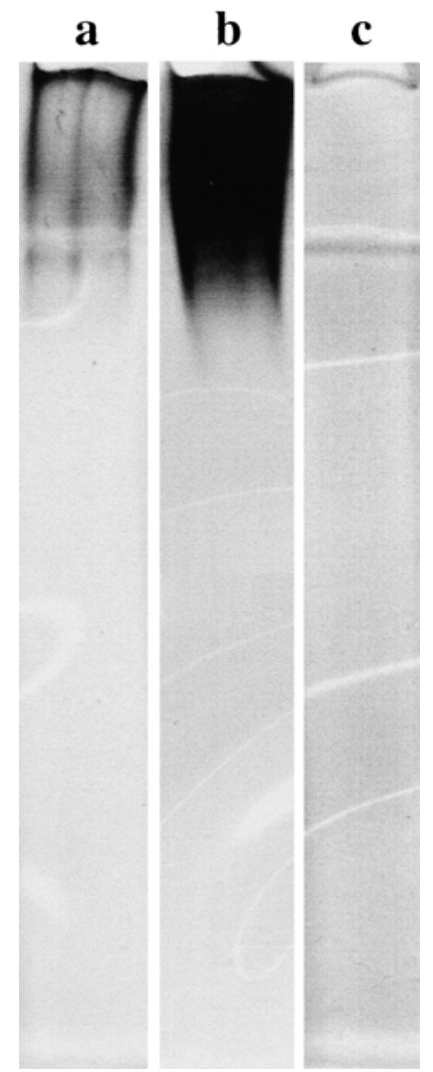

Fig. 1. P. clarkii HLS proteins separated on a $4.5 \%$ gel for native PAGE and stained with 4-methyl catechol: (a) HLS proteins electrophoresed and stained with indicated substrate; (b) gel was pretreated with SDS before substrate addition; (c) HLS sample was boiled $\left(100^{\circ} \mathrm{C}\right.$ for $5 \mathrm{~min}$ ) before electrophoresis and pretreated with SDS before substrate addition. A total of $20 \mu \mathrm{g}$ of protein was loaded in each well.

migration pattern (Fig. 2c). Cresolase activity was associated with the slow migrating bands (Fig. 2f), while laccase activity was associated with the fast migrating bands (Fig. 2i).

The thermostability of PO assayed with catechol and DAB was investigated at $20,30,50,60,70,80,90$ and $100^{\circ} \mathrm{C}$. HLS samples were pretreated at the indicated temperatures for $5 \mathrm{~min}$ before SDS-PAGE. Catecholase activity appeared to be inhibited above $70^{\circ} \mathrm{C}$ (Fig. 3a ). A similar pattern of activity was observed for the laccase activity gel (Fig. 3b). The faint activity bands in both enzymatic assays seem to be more resistant to high temperatures.

The effect of $\mathrm{pH}$ on the detection of activity showed an increase of PO activity as $\mathrm{pH}$ was increased (Fig. $4 \mathrm{a}-\mathrm{c}$ ). Catecholase activity was observed at a wide range of $\mathrm{pH}$ values. Activity began to appear at $\mathrm{pH} 4$ (Fig. 4a). Cresolase and laccase activities followed a similar pattern, but activity appeared at $\mathrm{pH} 5.5$ (Fig. $4 \mathrm{~b}, \mathrm{c}$ ). Hydroquinone was used to test for laccase activity due to the oxidation of DAB at alkaline $\mathrm{pH}$.

PO activity associated with haemocyte membranes (HMS) was restricted to high molecular mass bands in SDS-PAGE gels (Fig. 5). PO activity bands with 


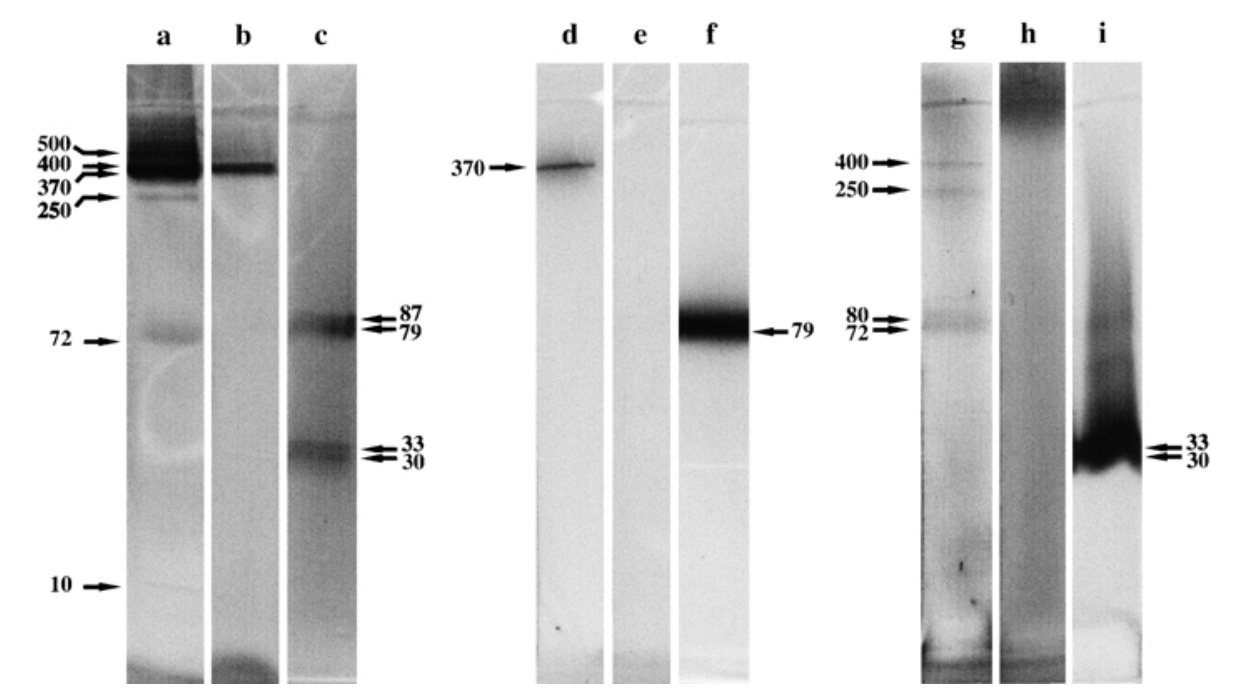

Fig. 2. P. clarkii HLS proteins separated on a $4-20 \%$ gradient gel for SDS-PAGE:

(a) gel incubated with 4-methyl catechol for catecholase activity; (b) same as in (a), but pre-treated with $10 \mathrm{~mm}$ DETC; (d) gel incubated with tyrosine methyl ester for cresolase activity; (e) same as in (d), but pre-treated with 10 mM DETC; (g) gel incubated with DAB for laccase activity; (h) same as in (g), but pre-treated with $10 \mathrm{~mm}$ DETC; (c), (f) and (i), purified mushroom tyrosinase control incubated with 4-methyl catechol, tyrosine methyl ester and DAB, respectively. Protein loaded in catecholase, cresolase and laccase gels were $4.5,2.5$ and $2.5 \mu \mathrm{g}$, respectively. Mushroom tyrosinase was loaded at a concentration of $1 \mu \mathrm{g}$.

molecular masses less than $300 \mathrm{kDa}$ were not observed in HMS, contrary to HLS (see Fig. 1). The different treatments used to elute PO activity from haemocyte membranes seems to result in different patterns of PO activity bands (Fig. 5 a-e). However, when all treatments were incubated with trypsin $\left(1 \mathrm{mg} \mathrm{ml}^{-1}\right)$ before SDS-PAGE, two PO activity bands of 320 and $280 \mathrm{kDa}$ were observed in all treatments (data not shown). HMS did not stain for cresolase and laccase activity.

\section{Discussion}

The HLS preparation procedure and adapted PO activity gels were able to produce a $72 \mathrm{kDa} \mathrm{PO}$ band that is similar to the $76 \mathrm{kDa}$ molecular mass of purified crayfish haemocytes proPO (Aspán \& Söderhäll, 1991). The deduced amino acid sequence of a cDNA cloned proPo from Pacifastacus leniusculus codes for a protein of $80 \mathrm{kDa}$ (Aspán et al., 1995). This molecular mass corresponds with another PO activity band of approximately $80 \mathrm{kDa}$ which stained with DAB, hydroquinone and with catechol in DMG (see Figs 2 and 4). Purified proPO from Galleria mellonella is composed of two subunits of 80 and $83 \mathrm{kDa}$ which are detectable in the presence of SDS under non-reducing conditions (Kopácek et al., 1995). The proPO gene, isolated from a cDNA library of Hyphantria cunea, encodes two polypeptides with molecular masses of 78.2 and $80.2 \mathrm{kDa}$ (Park et al., 1997). Purified Manduca sexta proPO contains 


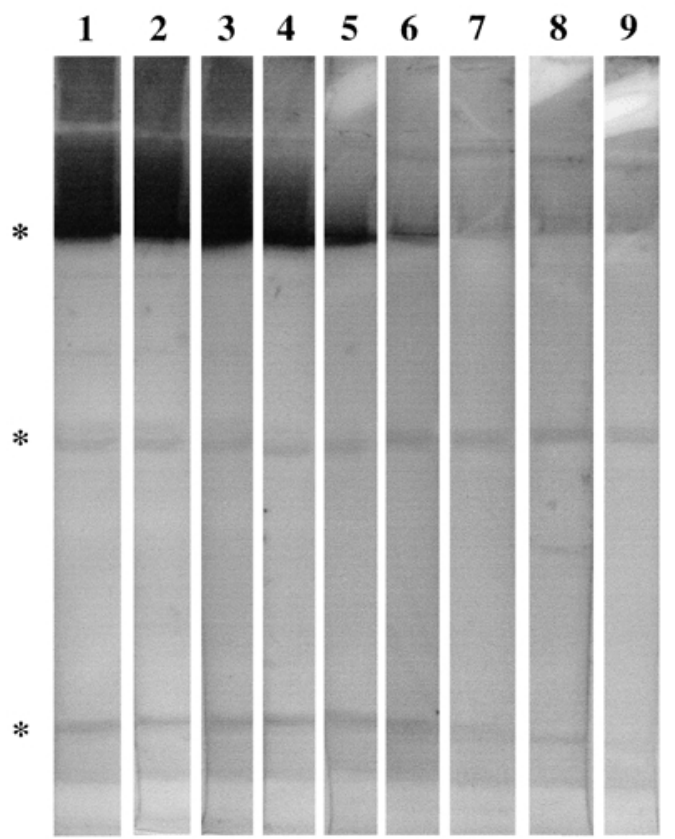

(a)

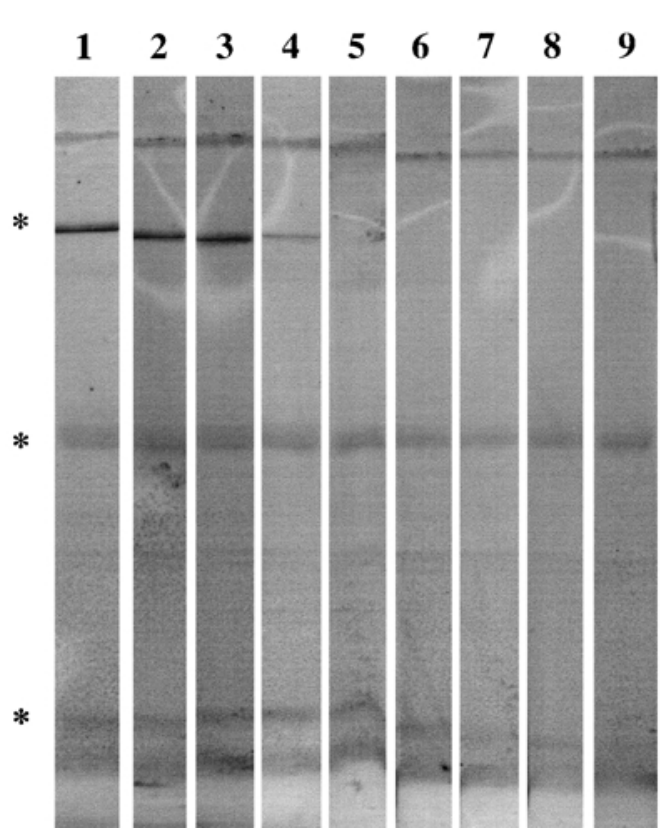

(b)

Fig. 3. P. clarkii HLS proteins separated on $4-20 \%$ gradient SDS-PAGE gels and developed in (a) 4-methyl catechol and (b) DAB. Before electrophoresis HLS samples were incubated at different temperatures for $5 \mathrm{~min}$, starting at (1) $20^{\circ} \mathrm{C}$ up to (9) $100^{\circ} \mathrm{C}$ in 10 degree increments. Asterisk denote high, intermediate and low molecular mass PO activity bands depicted in previous figures. A total of $17 \mu \mathrm{g}$ of protein was loaded in each well. 

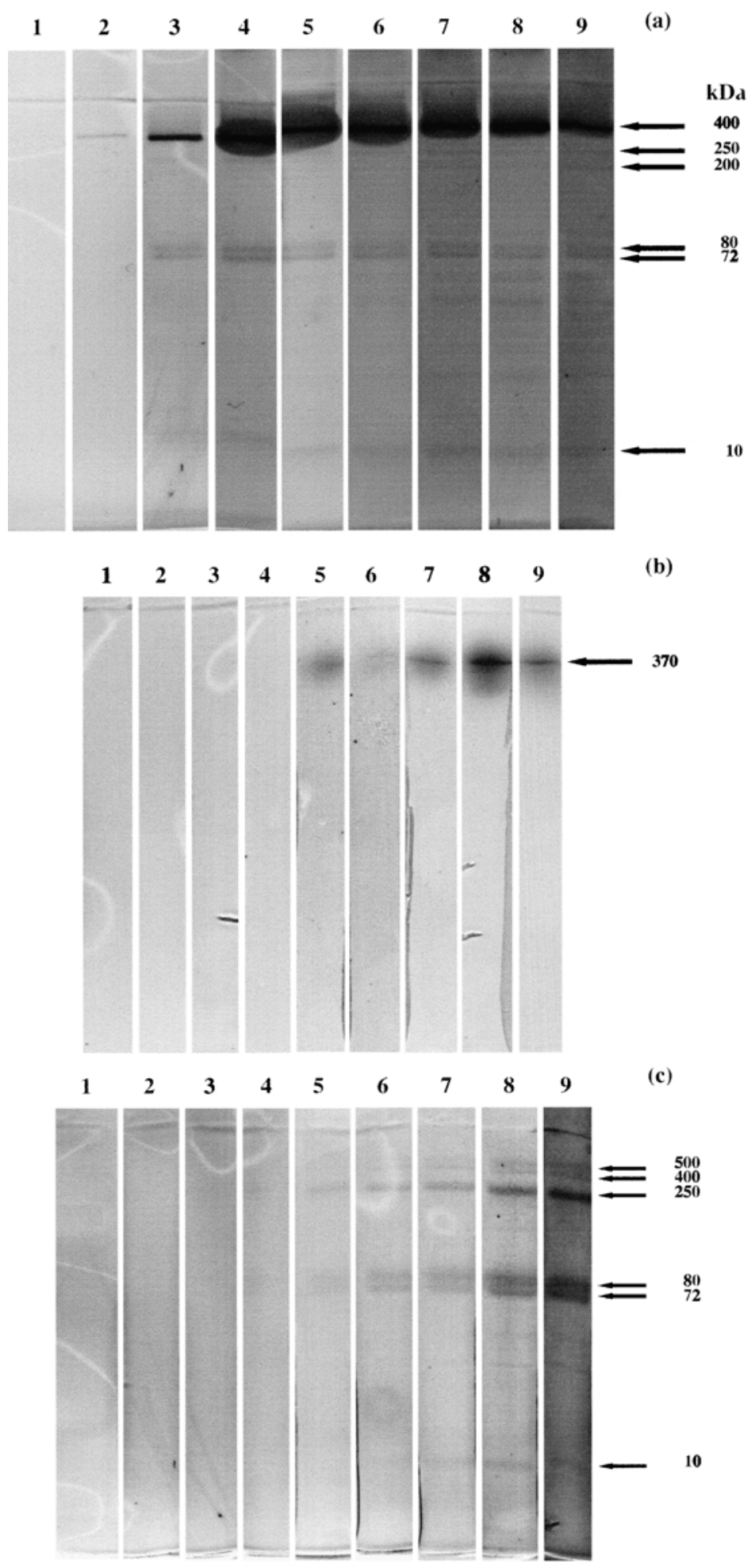

Fig. 4. For legend see facing page. 


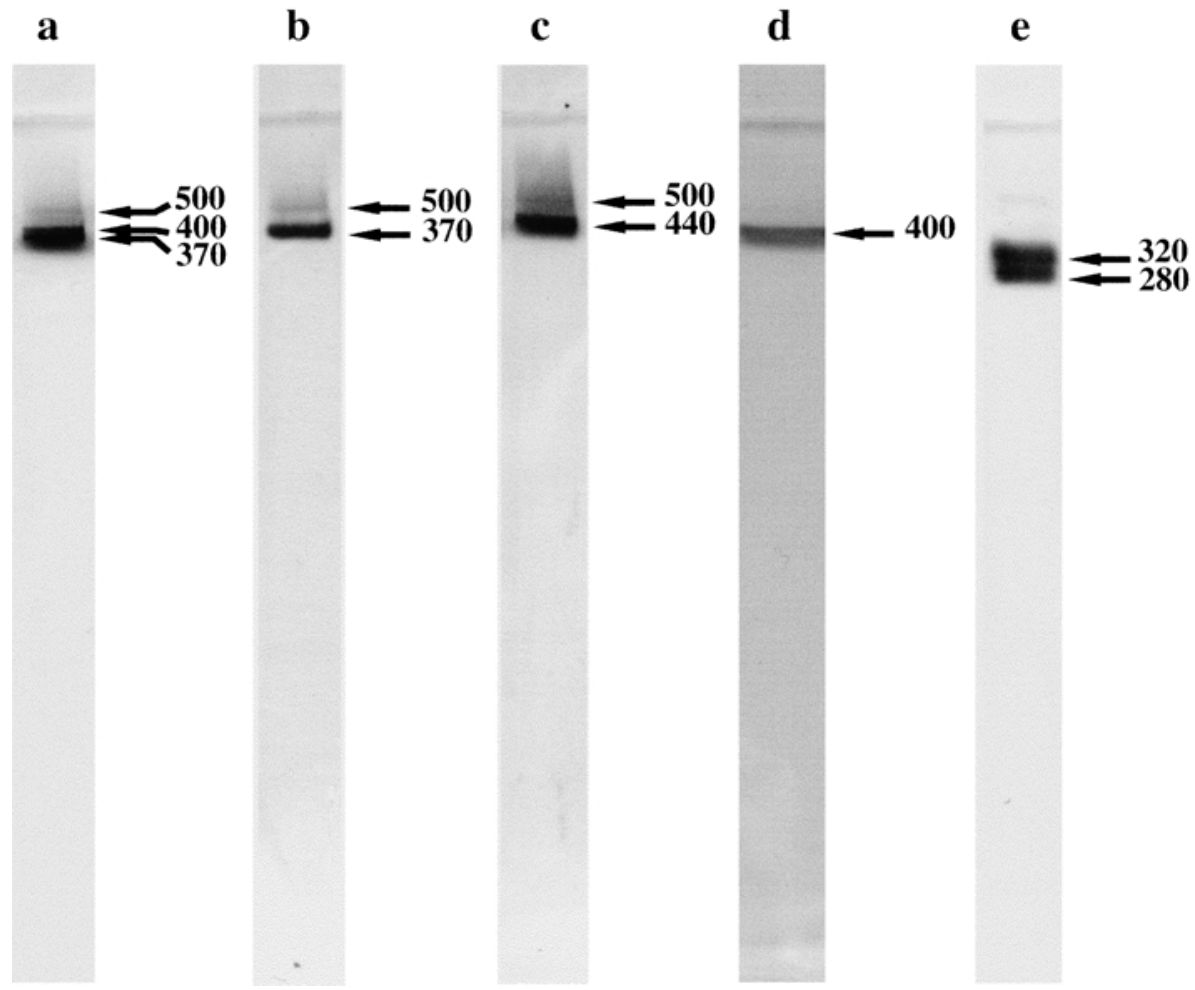

Fig. 5. P. clarkii HMS in 4-20\% gradient SDS-PAGE. PO activity associated with membranes was assayed with 4-methyl catechol after the following treatments (see Materials and Methods): (a) LyB; (b) LyB plus 1\% cholic acid; (c) LyB plus 1\% Triton X-100; (d) LyB plus 0.5 M NaCl; (e) LyB plus $1 \mathrm{mg} \mathrm{ml}^{-1}$ trypsin. Protein determination was affected by extraction procedure, but same amount of extraction was loaded in each well.

two polypeptides of 78 and $80 \mathrm{kDa}$ estimated from SDS-PAGE (Jiang et al., 1997a). A cDNA library from Anopheles gambiae haemolymph produced two different proPO clones with deduced molecular masses of 78 and $78 \cdot 6 \mathrm{kDa}$ (Jiang et al., 1997b). According to these reports, it is not surprising that bands of PO activity with similar molecular masses were detected in the present SDS-PAGE gels.

Partially or fully active PO seems to form large aggregates of higher molecular mass relative to inactive PO (Ashida \& Yoshida, 1988; Andersson et al., 1989; Aspán \& Söderhäll, 1991). Aggregates of proPO, PO, and an interleukin 1-like protein has been shown to have a molecular mass of $400 \mathrm{kDa}$ in Manduca sexta (Beck et al., 1996). Partial activation of proPO in the present

Fig. 4. P. clarkii HLS in 4-20\% gradient SDS-PAGE. PO activity was assayed in nine different $\mathrm{pH}$ values, starting with 3.5 (1) up to 7.5 (9) in 0.5 increment units. Gels were developed in three different substrates: (a) 4-methyl catechol; (b) tyrosine methyl ester and (c) hydroquinone. Protein loaded in each well for gels a, b and c, were $5 \cdot 5,15$ and $14 \mu \mathrm{g}$, respectively. 
HLS preparation or during SDS-PAGE would explain the high molecular mass observed in the PO activity gels. However, electrophoresis of the HLS preparation under non-denaturing conditions in native PAGE showed little PO activity unless the gel was subsequently treated with SDS when PO activity was enhanced. Thus, the presence of SDS is able to trigger the activation of proPO and hence its possible polymerisation to itself or other proteins under the denaturing conditions of SDS-PAGE. It is interesting to note that a monospecific antiserum preparation against crayfish proPO is able to bind to the $76 \mathrm{kDa}$ protein (molecular mass of purified proPO), but is unable to recognise any other protein in crude extracts from crayfish haemocytes after SDS-PAGE (Aspán et al., 1995). It is not clear whether in this last report crude extracts were boiled prior to SDS-PAGE, and thus protein aggregates might have been broken up. The epitope recognised by the monospecific antiserum might also have been masked by protein aggregates.

The presence of several PO activity bands in the HLS preparations can also be related to enzyme isoforms. In both the white shrimp Penaeus setiferus and the pink shrimp $P$. duorarum, two enzyme isoforms have been identified (Chen et al., 1997). The white shrimp isoforms are 20 and $25 \mathrm{kDa}$, and the pink shrimp isoforms are 30 and $35 \mathrm{kDa}$. Tissue extracts from Ceratitis capitata larvae show several molecular forms with tyrosinase activity after SDS-PAGE (Charalambidis et al., 1994). Mushroom tyrosinases have also been reported to be present in multiple forms (Bouchilloux et al., 1963; Jolley \& Mason, 1965). The PO band with lowest molecular mass in the present work on crayfish had a molecular mass of $10 \mathrm{kDa}$. This was present in the gels stained with catechol and hydroquinone. This molecular mass band region did not present cresolase activity. $\mathrm{PO}$ activity in this region is not likely to be an assay artifact since it stained differentially with catechol, DAB, hydroquinone and tyrosine. It was inhibited when the gel was pretreated with DETC as compared to nonpretreated controls, and its PO activity was impaired at temperatures higher than $70^{\circ} \mathrm{C}$. It is possible that the $10 \mathrm{kDa}$ band is a degradation product that retains some $\mathrm{PO}$ activity. This degradation product might only bear one of the two putative Cu-binding centers of crayfish proPO (Aspán et al., 1995), important for enzyme activity. Based on a cDNA clone of crayfish proPO (Aspán et al., 1995), a polypeptide that would contain the two putative Cu-binding centers would have a molecular mass $>28 \mathrm{kDa}$.

The use of DETC, a copper chelator and PO inhibitor, readily abolished all detectable cresolase and laccase and most of the catecholase activities. This supports the action of phenoloxidases in the activity bands observed in the present study. Further, horseradish peroxidase was able to oxidise methyl catechol, but was not inhibited by DETC (data not shown). PO activity gels are particularly suitable for inhibition studies, because thiol compounds like DETC can be removed from the gels before substrate addition and thus avoiding the formation of colorless adducts (Sanada et al., 1972). Therefore, only Cu-containing enzymes like PO can present inhibition of activity as opposed to iron-containing enzymes like peroxidase.

High temperature sensitivity of PO activity of high and low molecular mass bands supports the enzymatic nature of the substrate oxidation. High temperature resistance of $\mathrm{PO}$ intermediate molecular mass bands (i.e. 72 and $80 \mathrm{kDa}$ ) 
resembles the cuticular laccase-type enzyme B of Calliphora vicina (Barrett \& Andersen, 1981).

Substrate specificity of enzyme activity showed a strong catecholase reaction in all preparations. Methyl catechol was readily oxidised, followed by dopamine and L-DOPA estimated by the rate of visual development of activity bands on the gels (data not shown). Similar substrate preferences have been reported using different PO assay techniques (Barrett \& Andersen, 1981; Hall et al., 1995). Cresolase activity confirmed the presence of a tyrosinase-type PO in $P$. clarkii haemocytes. However, detection of laccase activity is surprising since this enzyme is believed to be restricted to integumental tissues where its key function is thought to be involved in cuticle sclerotisation (Barrett, 1987b; Charalambidis et al., 1994). Interestingly, laccase activity assayed either with $\mathrm{DAB}$ or hydroquinone was not detected in the region corresponding to the cresolase band at $370 \mathrm{kDa}$. This agrees with the contention that phenoloxidases of the tyrosinase type have cresolase and catecholase activity, and laccases are able to oxidise $o$ - or $p$-diphenols, but not monophenols. This enzymatic specificity was confirmed by the differential staining of purified mushroom tyrosinase included in the assays as a control. Haemolymph of immune reactive arthropods might benefit from the presence of laccase activity that could exert its action in the hardening of humoral or cellular capsules around invading parasites, which might explain its presence in crayfish haemocytes. Such a mechanism has been proposed for cellular capsule formation in Drosophila (Nappi et al., 1992).

Catecholase showed the widest range of $\mathrm{pH}$ activity. A similar pattern has been reported on isolated pre-phenoloxidase from the silkworm Bombyx mori (Ashida, 1971). In this last report, L-DOPA oxidation was reduced to $25 \%$ at $\mathrm{pH} 4 \cdot 5$, increased to $75 \%$ at $\mathrm{pH} 5$ and $100 \%$ at $\mathrm{pH}$. Crayfish cresolase activity had a relatively higher $\mathrm{pH}$ value for optimum activity than the corresponding catecholase activity. This activity was inhibited below $\mathrm{pH} 5.5$. In the table beet leaves cresolase activity increased at $\mathrm{pH}$ values above 4 and peaked at pH 5·5, maintaining high activity to about pH 7 (Escribano et al., 1997a). The optimum $\mathrm{pH}$ for insect cuticle-associated laccase activity ranges from $4 \cdot 3-4 \cdot 9$ (Barrett, 1987a, b). In the present report, crayfish laccase activity was faint at $\mathrm{pH} 5$ and peaked between $\mathrm{pH} 8$ and 9. This higher $\mathrm{pH}$ preference might be related to its unusual localisation of this enzyme in crayfish haemocytes. Laccase is believed to be present only in arthropod cuticles where it mediates sclerotisation (Barret, 1987b).

Immunofluorescence analysis has demonstrated the presence of proPO on the surface of insect haemocytes (Charalambidis et al., 1996). In plants, the association of PO with membranes has been established (Escribano et al., 1997a, b). Our ability to elute PO easily from crayfish haemocyte membranes suggests this enzyme might be only weakly associated to the membranes. Similar weak associations of plant PO to thylakoid membranes has been documented (Robinson \& Dry, 1991). If the putative haemocytic membrane PO activity is the result of unspecific binding of soluble PO during HLS preparation, then a similar banding pattern of PO activity should have been developed, as was seen in the HLS preparations. PO readily attaches to surfaces when active (Söderhäll et al., 1979). Since the HLS preparations were 
shown to contain PO largely in an inactive form, PO binding to haemocyte membranes should have been avoided. Besides, the presence of EDTA in the lysing buffer should prevent PO attachment, because calcium ions are necessary for this property (Söderhäll et al., 1979). More importantly, the banding patterns of PO activity from membranes were dissimilar to HLS and cresolase activity was never observed in any of the membrane preparations, strongly suggesting that the membrane and HLS enzymes are different. The different PO enzymatic activity of membrane-bound and soluble PO has also been reported for the helminth, Fasciola gigantia, where PO is also believed to be involved in the pathogen defence mechanisms (Nellaiappan et al., 1989). A haemocyte surface PO might be important in the crayfish cellular defence against bacteria since it has been shown that cell-surface PO is a prerequisite for LPS internalisation in Ceratitis capitata haemocytes (Charalambidis et al., 1996).

In summary we have presented a preliminary characterisation of phenoloxidase activities in gel-immobilised proteins from $P$. clarkii HLS and HMS preparations. We demonstrate the presence of cresolase, catecholase and laccase activities in the crayfish HLS. The multiple bands of PO activity may be due to both protein aggregation and PO isoforms based on difference in substrate preferences, $\mathrm{pH}$ optima and temperature sensitivity. The detection of cresolase and catecholase activities in crayfish haemocytes agrees with the reports of tyrosinase-type activity that purified arthropod proPO has shown. However, laccase activity has not been reported before in arthropod haemocytes. Since this enzymatic activity is important in cuticle sclerotisation, it is possible that this enzyme might be important in the formation of capsules around parasites too big to be phagocytosed. A membrane bound PO activity is suggested, based on the PO activity of HMS preparations. The enzymatic properties of the different PO activities and associated molecular masses could be used to better determine the roles of these activities in the pathogen defence system of crayfish.

This work was supported by funds from the Louisiana Education Quality Support Fund (LEQSF-RD-32) and the Department of Biology, University of Southwestern Louisiana.

\section{References}

Andersson, K., Sun, S., Boman, H. \& Steiner, H. (1989). Purification of the prophenoloxidase from Hyalophora cecropia and four proteins involved in its activation. Insect Biochemistry 19, 629-637.

Ashida, M. (1971). Purification and characterization of pre-phenoloxidase from hemolymph of the silkworm Bombyx mori. Archives of Biochemistry and Biophysics 144, 749-762.

Ashida, M. \& Yoshida, H. (1988). Limited proteolysis of prophenoloxidase during activation by microbial products in insect plasma and effect of phenoloxidase on electrophoretic mobilities of plasma proteins. Insect Biochemistry 18, 11-19.

Aspán, A., Huang, T., Cerenius, L. \& Söderhäll, K. (1995). cDNA cloning of prophenoloxidase from the freshwater crayfish Pacifastacus leniusculus and its activation. Proceedings of the National Academy of Sciences. USA 92, 939-943.

Aspán, A. \& Söderhäll, K. (1991). Purification of prophenoloxidase from crayfish blood cells, and its activation by an endogenous serine proteinase. Insect Biochemistry 21, 363-373. 
Barrett, F. (1984). Wound-healing phenoloxidase in larval cuticle of Calpodes ethlius (Lepidoptera: Hesperiidae). Canadian Journal of Zoology 62, 834-838.

Barrett, F. (1987a). Characterization of phenoloxidases from larval cuticle of Sarcophaga bullata and a comparison with cuticular enzymes from other species. Canadian Journal of Zoology 65, 1158-1166.

Barrett, F. (1987b). Phenoloxidases from larval cuticle of the sheep blowfly, Lucilia cuprina: characterization, developmental changes, and inhibition by antiphenoloxidase antibodies. Archives of Insect Biochemistry and Physiology 5, 99-118.

Barrett, F. \& Andersen, S. (1981). Phenoloxidases in larval cuticle of the blowfly, Calliphora vicina. Insect Biochemistry 11, 17-23.

Beck, G., Cardinale, S., Wang, L., Reiner, M. \& Sugumaran, M. (1996). Characterization of a defense complex consisting of interleukin 1 and phenol oxidase from the hemolymph of the Tobacco hornworm, Manduca sexta. The Journal of Biological Chemistry 271, 11035-11038.

Binnington, K. \& Barrett, F. (1988). Ultrastructural localization of phenoloxidases in cuticle and haemopoietic tissue of the blowfly Lucilia cuprina. Tissue \& Cell $\mathbf{2 0}$, 405-419.

Boss, P., Gardner, R., Janssen, B. \& Ross, G. (1995). An apple polyphenol oxidase cDNA is up-regulated in wounded tissues. Plant Molecular Biology 27, 429-433.

Bouchilloux, S., McMahill, P. \& Mason, H. S. (1963). The multiple forms of mushroom tyrosinase. The Journal of Biological Chemistry 238, 1699-1707.

Canicatti, C. \& Götz, P. (1991). DOPA oxidation by Holothuria polii coelomocyte lysate. Journal of Invertebrate Pathology 58, 305-310.

Cárdenas, W. \& Dankert, J. R. (1997). Phenoloxidase specific activity in the red swamp crayfish Procambarus clarkii. Fish \& Shellfish Immunology 7, 283-295.

Charalambidis, N., Bournazos, S., Zervas, C., Katsoris, P. \& Marmaras, V. (1994). Glycosylation and adhesiveness differentiate larval Ceratitis capitata tyrosinases. Archives of Insect Biochemistry and Physiology 27, 235-248.

Charalambidis, N., Foukas, L., Zervas, C. \& Marmaras, V. (1996). Hemocyte surface phenoloxidase (PO) and immune response to lipopolysaccharide (LPS) in Ceratitis capitata. Insect Biochemistry and Molecular Biology 26, 867-874.

Chen, J., Charest, D., Marshall, M. \& Wei, C. (1997). Comparison of two treatment methods on the purification of shrimp polyphenol oxidase. Journal of the Science of Food and Agriculture 75, 12-18.

Escribano, J., Cabanes, J., Chazarra, S. \& García-Carmona, F. (1997a). Characterization of monophenolase activity of table beet polyphenol oxidase. Determination of kinetic parameters on the tyramine/dopamine pair. Journal Agriculture and Food Chemistry 45, 4209-4214.

Escribano, J., Cabanes, J. \& García-Carmona, F. (1997b). Characterisation of latent polyphenol oxidase in table beet: effect of sodium dodecyl sulphate. Journal of the Science of Food and Agriculture 73, 34-38.

Götz, P. \& Boman, H. (1985). Insect immunity. In: Comprehensive Insect Physiology, Biochemistry and Pharmacology. (G. Kerkut \& L. Gilbert, eds) pp. 453-485. Oxford: Pergamon Press.

Hall, M., Scott, T., Sugumaran, M., Söderhäll, K. \& Law, J. H. (1995). Proenzyme of Manduca sexta phenol oxidase: purification, activation, substrate specificity of the active enzyme, and molecular cloning. Proceedings of the National Academy of Sciences 92, 7764-7768.

Jackson, A. D., Smith, V. J. \& Peddie, C. M. (1993). In vitro phenoloxidase activity in the blood of Ciona intestinalis and other ascidians. Developmental and Comparative Immunology 17, 97-108.

Jiang, H., Wang, Y., Korochkina, S., Benes, H. \& Kanost, M. (1997b). Molecular cloning of cDNAs for two pro-phenol oxidase subunits from the malaria vector, Anopheles gambiae. Insect Biochemistry and Molecular Biology 27, 693-699.

Jiang, H., Wang, Y., Ma, C. \& Kanost, M. (1997a). Subunit composition of pro-phenol oxidase from Manduca sexta: molecular cloning of subunit proPO-P1. Insect Biochemistry and Molecular Biology 27, 835-850. 
Jolley, R. L. \& Mason, H. S. (1965). The multiple forms of mushroom tyrosinase, interconversion. Journal of Biological Chemistry 240, PC1489-PC1491.

Kopácek, P., Weise, C. \& Götz, P. (1995). The prophenoloxidase from the wax moth Galleria mellonella: purification and characterization of the proenzyme. Insect Biochemistry and Molecular Biology 25, 1081-1091.

Nappi, A., Vass, E., Carton, Y. \& Frey, F. (1992). Identification of 3,4dihydroxyphenylalanine, 5,6-dihydroxyindole, and N-acetylarterenone during eumelanin formation in immune reactive larvae of Drosophila melanogaster. Archives of Insect Biochemistry and Physiology 20, 181-191.

Nellaiappan, K. \& Banu, M. (1991). Demonstration of monophenoloxidase activity of tyrosinase after electrophoresis. Biotechnic \& Histochemistry 66, 125-130.

Nellaiappan, K., Devasundari, A. F. \& DhandayuthapanI, S. (1989). Properties of phenol oxidase in Fasciola gigantica. Parasitology 99, 403-407.

Nellaiappan, K. \& Vinayagam, A. (1986). A rapid method for detection of tyrosinase activity in electrophoresis. Stain Technology 61, 269-272.

Okun, M., Edelstein, L., Or, N., Hamada, G., Blumental, G., Donnellan, B. \& Burnett, J. (1972). Oxidation of tyrosine and dopa to melanin by mammalian peroxidase: the possible role of peroxidase in melanin synthesis and catecholamine synthesis in vivo. In Pigmentation: its genesis and biologic control. (V. Riley, ed.) pp. 571-592. New York: Appleton-Century-Crofts.

Park, D., Shin, S., Kim, M., Park, S., Lee, W., Brey, P. \& Park, H. (1997). Isolation and characterization of the cDNA encoding the prophenoloxidase of fall webworm, Hyphantria cunea. Insect Biochemistry and Molecular Biology 27, 983-992.

Perazzolo, L. \& Barracco, M. (1997). The prophenoloxidase activating system of the shrimp Penaues paulensis and associated factors. Developmental and Comparative Immunology 21, 385-395.

Robinson, S. \& Dry, I. (1991). Broad bean leaf polyphenol oxidase is a 60-kilodalton protein susceptible to proteolytic cleavage. Plant Physiology 99, 317-323.

Sanada, H., Suzue, R., Nakashima, Y. \& Kawada, S. (1972). Effect of thiol compounds on melanin formation by tyrosinase. Biochimica et Biophysica Acta 261, 258-266.

Smith, V. J. \& Söderhäll, K. (1983). Induction of degranulation and lysis of haemocytes in the freshwater crayfish, Astacus astacus by components of the prophenoloxidase activating system in vitro. Cell and Tissue Research 233, 295-303.

Smith, V. J. \& Söderhäll, K. (1991). A comparison of phenoloxidase activity in the blood of marine invertebrates. Developmental and Comparative Immunology 15, 251-261.

Söderhäll, K., Cerenius, L. \& Johansson, M. W. (1994). The prophenoloxidase activating system and its role in invertebrate defence. Annals of the New York Academy of Sciences 712, 155-161.

Söderhäll, K., Häll, L., Unestam, T. \& Nyhlén, L. (1979). Attachment of phenoloxidase to fungal cell walls in arthropod immunity. Journal of Invertebrate Pathology 34, $285-294$.

Thangaraj, T. \& Aruchami, M. (1992). Soluble cuticular phenoloxidase in the gypsy moth Lymantria dispar. Archives of Insect Biochemistry and Physiology 21, 65-74.

Thipyapong, P., Hunt, M. \& Steffens, J. (1995). Systematic wound induction of potato (Solanum tuberosum) polyphenol oxidase. Phytochemistry 40, 673-676. 